+ Supporting Information

\title{
An evaluation of flowsheet design approaches to improve energy efficiency in multi-stage membrane processes to recovery helium
}

\author{
M. Abdul Quader ${ }^{\mathrm{ab}}$ *, Thomas E. Rufford ${ }^{\mathrm{ab}}$, Simon Smart ${ }^{\mathrm{ac}}$
}

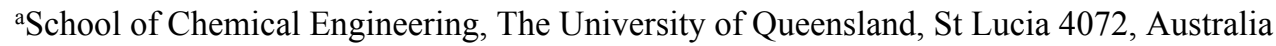

${ }^{\mathrm{b}}$ Australian Centre for LNG Futures (ACLNGF), School of Chemical Engineering, The University of Queensland, St Lucia 4072, Australia

'Dow Centre for Sustainable Engineering Innovation, School of Chemical Engineering, The University of Queensland, Brisbane, QLD 4072, Australia

* Contact: M. Abdul Quader (‥quader@uq.net.au) 


\section{Membrane module model description:}

\section{Solution-diffusion mechanism}

According to the solution-diffusion mechanism, the driving force across a gas-separation membrane is the pressure differential/fugacity $(\Delta \mathrm{p})$ between the feed side and the permeate side expressed as ${ }^{1}$ :

$$
\begin{aligned}
& J_{i}=\frac{P_{i}^{*}}{l} A_{m}\left(p_{f}, x_{i}-p_{p}, y_{i}\right) \\
& =\frac{P_{i}^{*}}{l} A_{m} \Delta p
\end{aligned}
$$

Where $J_{i}$ is the flux across the membrane $(\mathrm{kmol} / \mathrm{s}), P_{i}^{*}$ is the permeability value for component $i$ $\left(\mathrm{kmol} . \mathrm{m} /\left(\mathrm{s} . \mathrm{m}^{2}\right.\right.$. bar $\left.)\right), l$ is the membrane effective thickness $(\mu \mathrm{m}), A_{m}$ is the membrane area $\left(\mathrm{m}^{2}\right), x_{i}$ and $y_{i}$ are the mole fraction of the component $i$ in the feed and permeate sides, and $P_{f}$ and $P_{p}$ are the pressures in the feed side and permeate side, respectively. The permeability $P_{i}^{*}$ is also commonly expressed in barrer, where 1 barrer is equivalent to $3.348 \mathrm{kmol} . \mathrm{m} /\left(\mathrm{s} . \mathrm{m}^{2} . \mathrm{bar}\right)$.

\section{Module design}

In addition to the membrane material, the configuration of the membrane module is another significant influencing factor for helium separation. The separation process and economic performance of a membrane-based $\mathrm{He} / \mathrm{N}_{2}$ separation process depend on several parameters and assumptions. To investigate any techno-economic analysis, a correlation between input conditions, operating variables, and output variables and conditions must be clarified. In general, the input conditions are given by the feed stream and process design specifications, while the outcome has to be projected in terms of product target and economic indicators. In the framework of gas separation, for example, $\mathrm{He} / \mathrm{N}_{2}$ separation, the leading performance indicators are He recovery $(\mathbf{R})$, He purity $(\mathbf{P})$ and separation factor $\left(\alpha^{*}\right)$ for component He, given by

$$
\begin{aligned}
& R=\frac{F_{H e, p} \times(L) \times y_{H e, p}(L)}{F_{H e, f} \times y_{H e, f}} \\
& P=y_{H e, p}(L) \\
& \alpha^{*}=\frac{y_{H e, p}(L)\left[1-y_{H e, f}(L)\right]}{y_{H e, f}(L)\left[1-y_{H e, p}(L)\right]}
\end{aligned}
$$


Where $F$ indicate the molar flow rate of He, $y$ the molar mole fraction, and $L$ is the length of the module. The subscripts $f$ and $p$ refers to the component $\mathrm{He}$ in the feed and permeate side respectively.

Gas separation membrane module can be considered as a black box with one inlet stream (feed) and two outlet streams (retentate and permeate) as shown in Figure 1. In the development of the membrane module, the following assumption is made:

- Isothermal process

- Steady-state and did not consider Joule-Thomson effect through the membrane module

- Constant pressure at both sides of the membrane

- Constant membrane properties, i.e., selectivity and permeability independent from temperature, pressure and gas composition

- Negligible non-idealities such as fiber deformation, membrane swelling, membrane plasticization

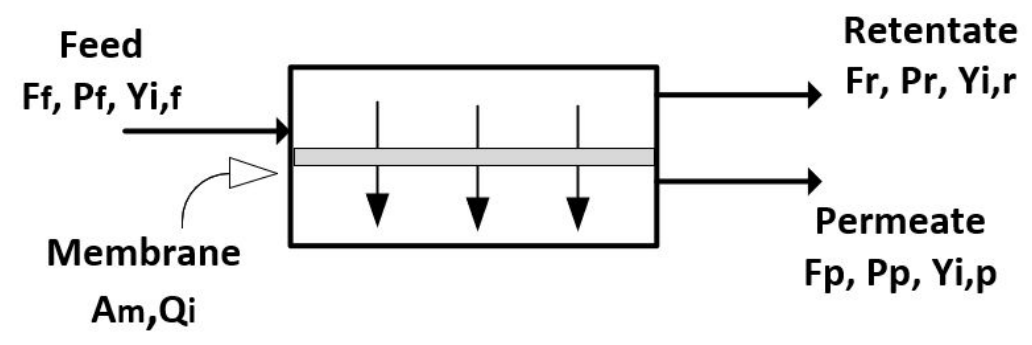

Figure S1: Schematic of membrane gas separation module.

Based on the above assumptions, the governing equations for a general membrane-based gas separation model are as follows.

Overall material balance equations:

$F_{f}=F_{p}+F_{r}$

Component material balance equations:

$F_{f} y_{i, f}=F_{p} y_{i, p}+F_{r} y_{i, r} \quad[i=1,2,3 \ldots . n-1]$

Where $n$ represents the number of components of gas mixture entering the membrane module. The materials balance can also be expressed in terms of flux across the membrane.

$F_{p}=\sum_{i}^{n} \int_{0}^{A} J_{i} d_{s}$ 
Where $J_{i}$ indicates the flux of the component $i$ and can be expressed through the solution-diffusion model. The membrane area $A$ can be expressed according to the module geometry such as, as a cylindrical if the module is hollow-fiber or as a plate if the module is spiral-wound.

Rate/flux equations: The solution-diffusion model states,

$J_{i}=\frac{P_{i}}{l}\left(p_{f} y_{i, f}-p_{p} y_{i, p}\right)$

$F_{p} y_{i, p}=A_{m} Q_{i}\left(p_{f} y_{i, f}-p_{p} y_{i, p}\right) \quad[i=1,2,3 \ldots n]$

Where $Q_{i}$ is the permeance (= permeability/effective membrane thickness) of the $i$ component through the membrane.

Compositions equations: It should be recalled that the sum of the molar fractions must always equal unity.

$\sum_{i}^{n} y_{i, f}=1$

$\sum_{i}^{n} y_{i, r}=1$

$\sum_{i}^{n} y_{i, p}=1$

To solve these equations, in the pioneering work of Waller and Steiner, the first proposed two models for modeling binary gas separation mixture through membranes: perfect mixing on both sides and no mixing on both sides. Later, Pan ${ }^{2}$ proposed a differential algorithm using the shooting method. Later on, an advanced method was developed by Coker et al. ${ }^{3}$ which used in our model. 

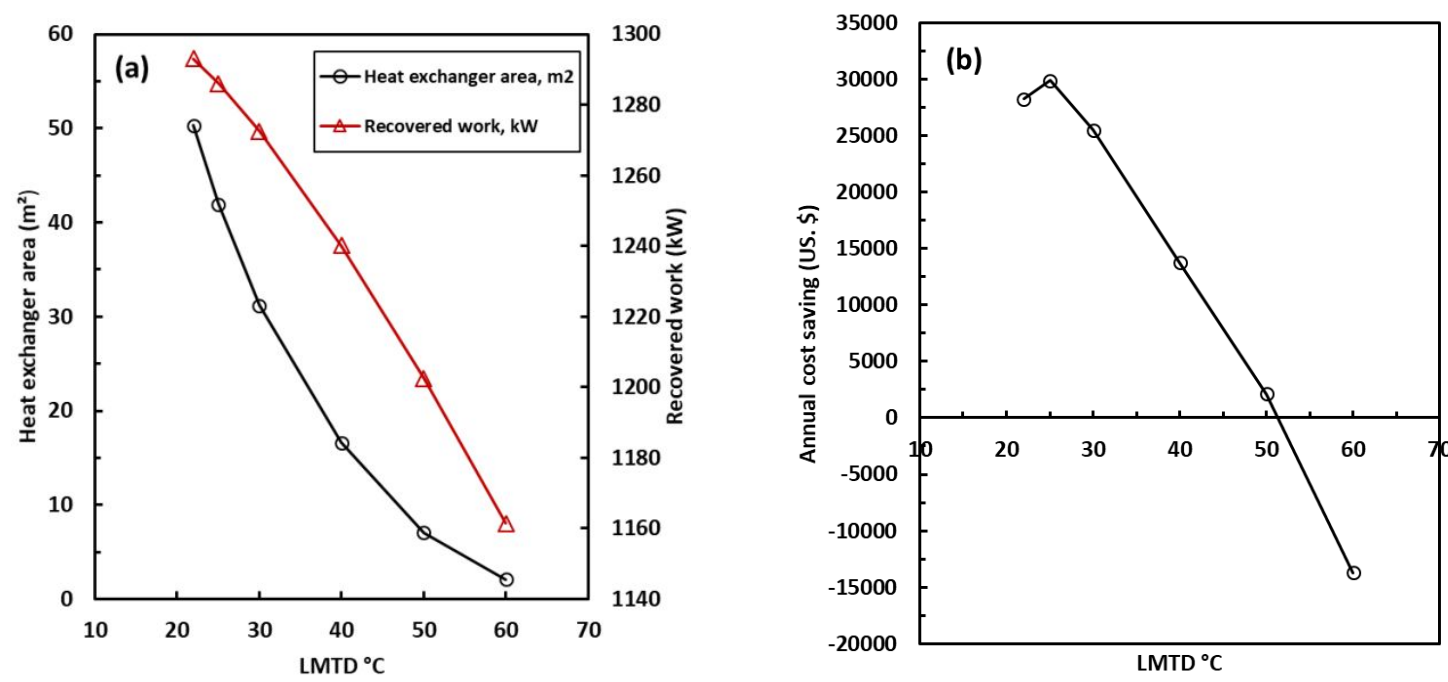

Figure S2: Two-stage membrane system: (a) the influence of LMTD on required heat transfer area and recovered work from expander (EXP), (b) dependence of annual cost saving on LMTD of heat exchanger (HEX).

Table S1: Key economic data for two-stage membrane systems for helium recovery from NRU off-gas at $80 \%$ recovery rate.

\begin{tabular}{llllll}
\hline $\begin{array}{l}\text { Schemes } \\
\text { Level }\end{array}$ & $\begin{array}{l}\text { All equipment } \\
\text { costs (US. \$) }\end{array}$ & $\begin{array}{l}\text { Membrane } \\
\text { costs (US. \$) }\end{array}$ & $\begin{array}{l}\text { Total plant } \\
\text { investment (US. \$) }\end{array}$ & $\begin{array}{l}\text { Power cost } \\
\text { (US. \$/year) }\end{array}$ & $\begin{array}{l}\text { Total plant } \\
\text { running cots } \\
\text { (US. \$/year) }\end{array}$ \\
\hline CP & $13,294,000$ & $2,242,580$ & $34,429,463$ & $1,546,642$ & $3,366,090$ \\
VP & $12,046,200$ & $44,336,911$ & $90,649,616$ & 187,309 & $7,838,578$ \\
CP+VP & $14,555,200$ & $11,334,213$ & $50,103,482$ & 784,880 & $3,990,848$ \\
CP+VP-1 & $14,373,600$ & $4,205,907$ & $26,200,080$ & 823,876 & $3,002,477$ \\
CP+EXP & $14,886,300$ & $2,242,580$ & $38,094,471$ & 970,916 & $2,925,545$ \\
CP+VP+EXP & $15,726,000$ & $11,334,213$ & $52,809,388$ & 473,720 & $3,777,598$ \\
\hline
\end{tabular}

\section{References:}

1. Baker, R.W., Membrane Technology and Applications. Third Edition ed. 2012: John Wiley \& Sons, Ltd

2. Pan, C., Gas separation by high-flux, asymmetric hollow-fiber membrane. AIChE Journal, 1986. 32(12): p. 2020-2027.

3. Coker, D., B. Freeman, and G. Fleming, Modeling multicomponent gas separation using hollow-fiber membrane contactors. AIChE journal, 1998. 44 (6): p. 1289-1302. 